\title{
Evolution of Choice of Solubility and Dissolution Media After Two Decades of Biopharmaceutical Classification System
}

\author{
Nadia Bou-Chacra, ${ }^{1}$ Katherine Jasmine Curo Melo, ${ }^{1}$ Ivan Andrés Cordova Morales, ${ }^{1}$ Erika S. Stippler, ${ }^{2}$ \\ Filippos Kesisoglou, ${ }^{3}$ Mehran Yazdanian, ${ }^{4}$ and Raimar Löbenberg ${ }^{5,6}$ (D)
}

Received 14 December 2016; accepted 11 April 2017; published online 17 May 2017

Abstract. The introduction of the biopharmaceutics drug classification system
(Biopharmaceutics Classification System (BCS)), in 1995, provided a simple way to describe
the biopharmaceutics behavior of a drug. Solubility and permeability are among the major
parameters, which determine the fraction dose absorbed of a drug substance and
consequently its chances to be bioavailable. The purpose of this review is to summarize the
evolution of the media used for determining solubility and dissolution and how this can be
used in modern drug development. Over the years, physiologically adapted media and
buffers were introduced with the intention to better predict the in vivo solubility and
dissolution of drug substances. Water, buffer solutions, compendial media, micellar
solubilization media, and biorelevant media are reviewed. At this time point, there is no
universal medium available which can be used to predict every drug substance's solubility or
a drug product's in vivo dissolution behavior. However, there have been many improvements
and additions made to media to optimize their in vivo predictability; for example, the current
phosphate concentrations in buffers seem to be too high to correlate with the carbonate
buffer concentrations in vivo. Biorelevant media were updated to correlate them better with
the composition of human intestinal fluids. The BCS was introduced into regulatory sciences
as a scientific risk management tool to waive bioequivalence studies under certain conditions.
Today's different guidance documents define the dose-solubility ratio differently. As shown
for amoxicillin, this can cause more confusion than certainty for globally operating
companies. Harmonization of BCS guidelines is highly desirable.

KEY WORDS: BCS; dissolution; IVIVC; solubility.

\section{INTRODUCTION}

The introduction of the biopharmaceutics drug classification system Biopharmaceutics Classification System (BCS), in 1995, provided a simple way to describe the biopharmaceutics behavior of a drug. Solubility and permeability are among the major parameters, which determine the

Electronic supplementary material The online version of this article (doi:10.1208/s12248-017-0085-5) contains supplementary material, which is available to authorized users.

${ }^{1}$ Faculty of Pharmaceutical Sciences, University of Sao Paulo, Sao Paulo, Brazil.

${ }^{2}$ United States Pharmacopeial Convention, Rockville, MD, USA.

${ }^{3}$ Merck \& Co., Inc., Kenilworth, NJ, USA.

${ }^{4}$ Teva Branded Pharmaceutical Products R\&D, West Chester, PA, USA.

${ }^{5}$ Faculty of Pharmacy and Pharmaceutical Sciences, University of Alberta, Edmonton, AB, Canada.

${ }^{6}$ To whom correspondence should be addressed. (e-mail: raimar@ualberta.ca) fraction dose absorbed of a drug substance and consequently its chances to be bioavailable. Solubility in this context is reported as aqueous solubility. Regulatory guidance classify Active Pharmaceutical Ingredients (API) according to their solubility in aqueous buffers. However, human physiology in the gastrointestinal tract is complex and can have a profound impact on the in vivo solubility of a drug substance. Physiologically adapted media and buffers were introduced over the past decades with the intention to better predict the in vivo solubility of drug substances. Similarly, dissolution methodologies were originally developed as quality control methods with limited or sometimes no in vivo relevance. However, today's regulatory agencies prefer to see more in vivo clinical relevant dissolution specifications and a discriminating dissolution method, which can detect changes in the drug product's critical quality attributes. Product development in a Quality by Design approach is impossible without utilizing the fundamental principles of the BCS with in vivo relevant measurements and predictions. This highlights the gap between regulatory classification based on the BCS and scientific mechanistic information based on the 
principles of the BCS needed to predict in vivo behavior/in vivo dissolution of APIs.

The purpose of this review is to summarize the evolution of the media used for determining solubility and dissolution and how this can be used in modern drug development. The literature search for this review paper was originally undertaken in September 2014 using four databases: ISI Web of Science, SciFinder, Scopus, and Google Scholar. These databases were carefully selected to allow identification of reports, dissertations, and conference contributions in addition to original studies published in scientific journals. No date or language restriction was applied to the searches. Update searches were subsequently performed in July 2016. The keywords and controlled languages were as follows: BCS, biorelevant media, dissolution, fasted state, fed state, drug solubility, intrinsic dissolution, simulated intestinal fluid, simulated gastric fluid, buffered dissolution media, apparent solubility, and dissolution rate. The total number of studies in this review was 51. Some of these studies utilized both methods (shake flask and dissolution testing) whereas 46 described using the shake flask method only and 20 studies used dissolution testing.

Drug solubility data for each media and its composition in the studies were extracted and tabulated. The information regarding the composition of dissolution media was also extracted from the official guidelines: European Medicines Agency (EMA), Food and Drug Administration (FDA), Health Canada, Brazilian Health Surveillance Agency (ANVISA), World Health Organization (WHO), and Brazilian, European, and United States pharmacopeias.

\section{SOLUBILITY IN AQUEOUS MEDIA}

From the biopharmaceutics perspective, aqueous solubility is an important primary physicochemical property of a drug substance. Solubility is defined as the amount of drug substance that dissolves into a solvent to achieve a saturated solution at constant temperature and pressure. Solubility is expressed in terms of maximum volume or mass of the solute that dissolves in a given volume or mass of a solvent (1).

The shake-flask method proposed by Higuchi and Connors (2) is today widely used in the determination of a drug's solubility. It determines the thermodynamic solubility of a drug substance after reaching equilibrium. An excess amount of drug substance is added to a specific medium at a specific temperature. Depending on the solubilization rate and the type of agitation used, equilibrium can be achieved within hours or days. The drug substance and the saturated solution can be separated via filtration or centrifugation during equilibration phase (3).

The United States Pharmacopeia (USP) describes solubility in more general terms and defines it as the number of parts by volume of solvent required to dissolve one part by weight of a solid, or one part by volume of a liquid (4) as described in Supplemental material 1.

Aqueous solubility as described by USP is normally reported as reference solubility in water at room temperature. However, in majority of cases, the $\mathrm{pH}$ value and the composition of a medium are important and can impact a drug substance's solubility; for example, functional groups, which are $\mathrm{pH}$ dependent, can be ionized and have a major impact on solubility (5).

Thus, solubility measured in water might not be indicative of solubility in the gastrointestinal tract, particularly for drugs, which are lipophilic and sparingly soluble.

\section{WATER}

The reviewed publications showed that different grades of water were used as media to determine the solubility of drug substance: double-distilled water (6-8); double deionized water (9), Milli-Q® purified water (10), $18.2 \mathrm{M} \Omega . \mathrm{cm} /$ $0.22 \mu \mathrm{m}$ (11); Milli-Q®ultrapure water, conductivity less than $0.1 \mu \mathrm{S} \mathrm{cm} \mathrm{(12,13);} \mathrm{ultrapure} \mathrm{water} \mathrm{Elix}{ }^{\circledR}$ Millipore (14); distilled water (5,15-21) deionized water (22-26); distilled, deionized, and filtered water (27); purified water (28-36); demineralized water (37). The type of water was not specified in 19 of 51 studies $(37 \%)(38-56)$.

If analytical grade water used in assays for quality control has no specific pharmacopeial monograph, it still has to meet the requirements of the USP purified water definition. The USP lists in its general chapter 1231 (4) the following non-monograph waters: distilled water, freshly distilled water, deionized water, freshly deionized water, deionized distilled water, filtered water, high-purity water, ammonia-free water, carbon dioxide-free water, ammoniaand carbon dioxide-free water, deaerated water, recently boiled water, oxygen-free water, water for BET, organic-free water, lead-free water, chloride-free water, and hot water. Each of these water types has specific properties that are needed for a specific assay. For example, water properties like deairing can change the dissolution rate of a drug product, although solubility is not impacted by it. This is used in the Performance Verification Test of the USP. If the dissolution medium is not sufficiently deaired, air bubbles can attach to powder and API particles of the used prednisone tablets. The powder particle will then float in the medium and less coning occurs under the paddle. This increases the dissolution rate and the test might fail to meet the dissolution specification.

\section{BUFFER SOLUTIONS}

This literature review found that phosphate buffer solutions, in the range of $\mathrm{pH} 5.8-8.0$, were employed in $32.6 \%$ of cases as medium for the shake-flask method (15 of 46 studies) $(8,11,19,31,32,37,41-43,45,46,48,51,57,58)$ and in $40.0 \%$ as dissolution medium ( 8 of 20 studies) $(10,11,22,24,51-53,56)$. Acetate buffer was used less frequently, in 4 of 46 studies $(8.7 \%)(41,42,45,49)$ as medium for the shake-flask method and in 2 of 20 studies (10.0\%) as dissolution medium $(52,56)$. Phosphate and acetate buffer solutions, which were claimed to have similar osmolality and ionic strength as the physiological fluids, were the most employed buffer solutions to determine solubility $(27.3 \%$ for the phosphate buffer and $9.1 \%$ for the acetate buffer).

The salt solubility of a drug depends not only on the concentration of the drug substance but also on that of the counter-ion. Buffers can introduce counter-ions with which the drug might precipitate due to lower solubility of the complex. On the other hand, high concentrations of the counter-ion can decrease the solubility of the salt, due to salting out effects. For example, sparingly soluble basic drugs, which are positively charged, can precipitate as phosphate salts in neutral or basic solutions due to $\mathrm{pH}$ change as reported by Kambayashi for dipyridamole and ketoconazole (59). Bergström reported similar solubility changes for a set of 25 drugs and described that a large variation in solubility was observed throughout the $\mathrm{pH}$ range. The 
substance-specific solubility was linked to the uncharged and completely charged drug species and the phosphate ion (60). Völgyi reports the salt solubility of diprenorphine hydrochloride, codeine hydrochloride and phosphate, and lidocaine hydrochloride and phosphate. In this study, chlorine ions besides phosphate ions caused solubility changes when the $\mathrm{pH}$ was adjusted with hydrochloric acid to lower the $\mathrm{pH}$ of the media (61).

Under such conditions, drugs, especially those with surface-active properties, can form micelles or selfassociated aggregates in the form of dimers, trimers, or higher-order oligomers (62). Many non-steroidal antiinflammatory drugs, such as indomethacin, diclofenac, ibuprofen, ketoprofen, and naproxen, tend to selfassociate by forming mixed-charged micelles or micellelike structures (63). In such systems, the solubility-pH profiles cannot be accurately described with the Henderson-Hasselbalch eq. (62). Avdeef showed after revaluation of published data from Higuchi 1953 (64) that dimers of drug molecules can cause deviations from the Henderson-Hasselbalch equation using the pDISOL-X program. This method is based on Volgyi's publication for the estimation of solubility, which is independed from the Henderson-Hasselbalch eq. (19).

In this report, only 1 of 43 studies selected used the modified Hank's balanced salt solution $(10,48)$, a bicarbonate-based buffer (Table I), for the shake-flask method. Krebs buffer, also a bicarbonate-based buffer, was used to determine drug solubility of ibuprofen (48) and as dissolution media for coated mesalazine tablets (65). This buffer was employed for intestinal absorption studies and provided an environment close to the physiological $\mathrm{pH}$ range and osmotic pressure. The disadvantage of the Krebs buffer is its sensitivity to storage conditions. Continuous sparking with $5 \% \mathrm{CO}_{2}$ and adding a layer of liquid paraffin on the top of the solution and/or the use of a completely sealed setup can stabilize the buffer (65).
McIlvaine buffer solutions with a citrate/phosphate buffer system were used in the range of $\mathrm{pH} 4.0$ to 6.8 $(6.5 \%)$, or 3 out of 46 studies used it for the shake-flask method $(5,27,48)$ and in 2 out of 20 studies as dissolution media $(10.0 \%)(5,27)$. Maleate $(32)$, Britton-Robinson universal $(19,25,39)$, and glycine buffers (31) were selected, respectively, in the rate of $2.2 \%$ ( 1 out of 46 studies), $6.5 \%$ (3 out of 46 studies), and $2.2 \%$ (1 out of 46 studies), for the shake-flask method.

As is evident, there are plenty of different buffer choices for measuring solubility. Future research has to demonstrate if one of them can be used as the universal first-choice medium. Phosphate buffer, which is currently the most oftenused medium, fails to be predictive for in vivo solubility of many poorly soluble drugs due to its lack in solubilization capacity $(66,67)$.

\section{USP COMPENDIAL MEDIA}

According to the FDA (68), simulated gastric fluid (USPSGF) containing pepsin and the corresponding medium SGF without enzyme (SGFblank) or simulated intestinal fluid containing pancreatin (USP-SIF) and the corresponding medium without enzyme (SIF-blank) better reflect the physiologic conditions of the stomach and the small intestine compared to other buffers. The composition of USP-SGF and USP-SIF are listed in Supplemental material 2 (4). Our review found that SGF was used with the shake-flask method in $17.4 \%$ cases ( 8 of 46 studies) $(13,15,17,21,26,40,41,49)$ and in $10.0 \%$ ( 2 of 20 studies) $(13,17)$ to perform dissolution tests; however, this medium is often prepared and used without enzyme.

Dressman et al. (69) described the use of a fasted state simulated gastric fluid, which contains sodium taurocholate and lecithin to better simulate the composition of human gastric fluid.

Table I. Composition of Phosphate Buffer (PB) and Hank's (Bicarbonate Buffer Modified) Used in the Solubility Test

\begin{tabular}{|c|c|c|c|c|c|}
\hline & $\begin{array}{l}\text { PB } \\
\text { Ph. Int. } 3^{\circ}\end{array}$ & PB Ph. Eur. 8.0 & PB Ph. Braz. $5^{\circ}$ & $\begin{array}{l}\text { PB } \\
\text { USP } 38\end{array}$ & Hank's buffer \\
\hline $\mathrm{KH}_{2} \mathrm{PO}_{4}(\mathrm{~g})$ & 34.00 & 1.36 & - & 1.36 & 0.06 \\
\hline $\mathrm{NaOH}(\mathrm{g})$ & - & 0.18 & - & 0.18 & - \\
\hline $\mathrm{Na}_{2} \mathrm{HPO}_{4}(\mathrm{~g})$ & 35.30 & - & 28.8 & - & - \\
\hline $\mathrm{K}_{3} \mathrm{PO}_{4}(\mathrm{~g})$ & - & - & 11.45 & - & - \\
\hline $\mathrm{Na}_{2} \mathrm{HPO}_{4} \cdot 12 \mathrm{H}_{2} \mathrm{O}(\mathrm{g})$ & - & - & - & - & 0.12 \\
\hline $\mathrm{NaCl}(\mathrm{g})$ & - & - & - & - & 7.94 \\
\hline $\mathrm{KCl}(\mathrm{g})$ & - & - & - & - & 0.40 \\
\hline D-glucose (g) & - & - & - & - & 0.91 \\
\hline $\mathrm{MgSO}_{4} \cdot 7 \mathrm{H}_{2} \mathrm{O}(\mathrm{g})$ & - & - & - & - & 0.20 \\
\hline $\mathrm{NaHCO}_{3}(\mathrm{~g})$ & - & - & - & - & 0.35 \\
\hline $\mathrm{CaCl}_{2} \cdot 2 \mathrm{H}_{2} \mathrm{O}(\mathrm{g})$ & - & - & - & - & 0.18 \\
\hline Deionized water (L) & 10.00 & 0.20 & 1.00 & 0.20 & 1.00 \\
\hline \multicolumn{6}{|l|}{ Properties } \\
\hline $\mathrm{pH}$ & 6.80 & - & - & 6.80 & 6.80 \\
\hline Osmolality (mOsmol/kg) & - & - & - & 115.00 & - \\
\hline Buffer capacity $(\mathrm{mmol} / \mathrm{L} / \mathrm{pH})$ & - & - & - & $18.60 \pm 0.10$ & $3.10 \pm 0.20$ \\
\hline Ionic strength $(\mathrm{mol} / \mathrm{L})$ & - & - & - & 0.08 & - \\
\hline
\end{tabular}

PB phosphate buffer, Ph. Int. Pharmacopeia International, Ph. Eur. European Pharmacopeia, Ph. Braz Brazilian Pharmacopeia, USP United States Pharmacopeia 
Such media are generally referred to as biorelevant media and will be discussed later under the intestinal segments of the GI tract.

In the case of USP-SIF, the $\mathrm{pH}$ value was changed from originally $\mathrm{pH} 7.5$ to $\mathrm{pH} 6.8$ in USP 25 (70). If $\mathrm{pH}$ values exceeding 7.5 are used, scientific justification should be provided, since this is considered outside the physiologically relevant $\mathrm{pH}$ range (9). However, there are USP monographs for which the $\mathrm{pH}$ value is 8.0 and even higher (71). For dichlorphenamide, chlorothiazide, ethacrynic, methyldopa and chlorotiazide, reserpine and chlorothiazide, and ursodiol tablets, the dissolution medium is 8.0; for oxymetholone and glyburite (micronized) tablets, the $\mathrm{pH}$ of the dissolution medium is 8.5; for nalidixic acid tablets, $\mathrm{pH}$ 8.6; for glyburide (non-micronized) tablets, $\mathrm{pH} 9.5$; and for sodium liothyronine tablets, $\mathrm{pH} 10$ (71). SIF-blank was used in $8.7 \%$ of the cases (or 4 out of 46) studies $(15,17,26,49)$ for shake flask and in $10.0 \%$ (2 out of 20 studies) $(17,24)$ as dissolution medium.

Comparing SIF-blank and standard pH 6.8 phosphate buffer, e.g., International Pharmacopeia (72) (Tables II and III), shows that there can be differences in the raw materials used to make them. However, as shown by Stippler et al., these buffers have similar properties including osmolality, ionic strength, and buffer capacity (72). In the same study, the media were considered interchangeable in the dissolution testing of ibuprofen, metronidazole, and indomethacin immediate-release solid oral dosage form. The study concluded that "only in specific cases where solubility is known to be affected by the cation does one need to be wary about substitution of the two cations for each other." This is in line with results reported by Almukainzi et al. (73). Here, the use of sodium and potassium buffers and SIF resulted in different disintegration times of cellulose-based hard shell capsules, which can result in different dissolution behaviors in vitro. In addition, Ropers et al. (74) reported the effect of $\mathrm{Na}+$ and $\mathrm{K}+$ counter-ions on the micelle formation of anionic surfactants like decyl and dodecyl sulfates. A decrease of the counter-ion binding in the order of $\mathrm{Na}+>\mathrm{K}+$ was reported. Thus, the use of sodium buffer instead of a potassium buffer might avoid precipitation of the surfactant due to counterion interaction.

The present report shows that $\mathrm{pH} 6.8$ phosphate buffer was the most commonly used medium $(35.0 \%)$ in dissolution studies. Aqueous buffer solutions and the compendial media mimic typical $\mathrm{pH}$ conditions, ionic strength, and osmolality conditions in the stomach or small intestine. Thus, they do not represent all aspects of physiological conditions in the gastrointestinal (GI) tract (e.g., viscosity, surface tension) (75) and usually offer, at best, empirical $a$ posteriori correlations with in vivo data (76). Also, the phosphate buffer failed to adequately discriminate and distinguish between products of torasemide, a class I drug according to the BCS, in a biowaiver approach. In this case, a medium at $\mathrm{pH} 5.0$ discriminated better among these products and was superior to the FDA-recommended medium (75).

Recently, Krieg et al. (77) compared carbonate and phosphate buffers. Their results are detailed discussed under bicarbonate buffers. However, they point out that buffer concentrations are important factors when it comes to in vivo relevance. Additionally, the above-listed media cannot simulate the influence of food ingestion on drug release. Therefore, the development of adequate test media and methods for both, fasted and fed states, that mimic certain physiological conditions was obvious.

\section{MICELLAR SOLUBILIZATION OF DRUGS}

Micellar systems can enhance solubility of poorly soluble drug substances and increase their bioavailability (78). Zangenberg et al. (79) developed a dynamic lipolysis model, where the rate of the hydrolysis of triglycerides was controlled by the addition of $\mathrm{Ca}^{2+}$ ions. This model simulates postprandial in vivo conditions during the digestion and absorption of lipid-based formulations. They

Table II. Composition of Simulated Intestinal Fluid in Fasted and Fed State

\begin{tabular}{|c|c|c|c|c|c|c|c|}
\hline Compound & FaSSIF & FaSSIF-V2 & FeSSIF & $\begin{array}{l}\text { FeSSIF } \\
\text { Early }\end{array}$ & $\begin{array}{l}\text { FeSSIF } \\
\text { Middle }\end{array}$ & $\begin{array}{l}\text { FeSSIF } \\
\text { Late }\end{array}$ & FeSSIF-V2 \\
\hline Bile salt (taurocholate) $(\mathrm{mM})$ & 3.00 & 3.00 & 15.00 & 10.00 & 7.50 & 4.50 & 10.00 \\
\hline Phospholipid (lecithin) (mM) & 0.75 & 0.20 & 3.75 & 3.00 & 2.00 & 0.50 & 2.00 \\
\hline Sodium dihydrogen phosphate (mM) & 28.65 & - & - & - & - & - & - \\
\hline Acetic acid (mM) & - & - & 144.00 & - & - & - & - \\
\hline Sodium chloride (mM) & 105.85 & - & 173.00 & 145.20 & 122.80 & 51.00 & 125.50 \\
\hline Maleic acid (mM) & - & - & - & 28.60 & 4450 & 8.09 & 55.02 \\
\hline Sodium hydroxide (mM) & - & - & 101.00 & 52.50 & 65.30 & 72.00 & 81.65 \\
\hline Glyceryl monooleate (mM) & - & - & - & 6.50 & 5,00 & 1.00 & 5.00 \\
\hline Sodium oleate $(\mathrm{mM})$ & - & - & - & 40.00 & 30.00 & 0.80 & 0.80 \\
\hline \multicolumn{8}{|l|}{ Properties } \\
\hline $\mathrm{pH}$ & 6.5 & 6.5 & 5 & 6.5 & 5.8 & 5.4 & 5.8 \\
\hline Osmolality (mOsmol/kg) & 270.00 & 180.00 & 635.00 & 400.00 & 390.00 & 240.00 & $390.00 \pm 10$ \\
\hline Buffer capacity (mEq/pH/L) & 10.00 & 10.00 & 76.00 & 25.00 & 25.00 & 15.00 & 25.00 \\
\hline
\end{tabular}

FaSSIF fasted state simulated intestinal fluid, FaSSIF-V2 fasted state simulated intestinal fluid version two, FeSSIF fed state simulated intestinal fluid, FeSSIF-V2 fed state simulated intestinal fluid version two 
Table III. Comparison Performance of Biorevelant Media and Aqueous Buffers in Drug Solubility

\begin{tabular}{|c|c|c|c|c|c|c|c|c|c|}
\hline Solubility (mg/mL) & Buffer & SGF & $\begin{array}{l}\text { Relative } \\
\text { Increase }\end{array}$ & Buffer & FeSSIF & Relative Increase & Buffer & FaSSIF & $\begin{array}{l}\text { Relative } \\
\text { Increase }\end{array}$ \\
\hline Compound & pH 1.2 & & & $\mathrm{pH} 5.0$ & & & pH 6.5 & & \\
\hline Indomethacin & 0.001 & 0.02 & 20.00 & 0.01 & 0.07 & 7.00 & 0.14 & 0.23 & 1.60 \\
\hline Sulindac & 0.007 & 0.03 & 4.60 & 0.35 & 0.40 & 1.10 & 0.53 & 0.77 & 1.50 \\
\hline Ibuprofen & 0.06 & 0.20 & 3.30 & 0.14 & 0.65 & 4.60 & 0.93 & 1.46 & 1.60 \\
\hline Napoxen & 0.005 & 0.10 & 20.00 & 0.09 & 0.20 & 2.20 & 0.77 & 1.21 & 1.60 \\
\hline
\end{tabular}

SGF simulated gastric fluid, FeSSIF fed state simulated intestinal fluid, FaSSIF fasted state simulated intestinal fluid

observed different dissolution profiles during lipolysis of probucol and danazol and linked this to their lipophilicity. Probucol has a $\log P$ value of over 10 and danazol, a value of 4.5 (79). The aqueous solubility of probucol depended on the partition of the drug between the lipophilic phase and the aqueous phase. The dissolution of danazol was found to be dependent on the solubilization capacity of the aqueous medium. This model was proposed as a method to investigate drug dissolution from formulations during lipolysis, simulating the fed state.

In a recent study, Ottaviani et al. (80) investigated the relationship between surfactants and their CMC (critical micellar concentration) on solubility enhancement of drug substances. The work shows that CMC is a better predictor in FaSSIF (fasted state simulated intestinal fluid) than lipophilicity $(\log \mathrm{D})$.

A study by Kaukonen et al. (81) compared the solubility of danazol and four other model drug substances between blank buffer solutions and micelles made from different triglyceride lipids. They investigated the impact of a digestion enzyme on the solubilization of poorly water-soluble drug substances (danazol, griseofulvin, diazepam, cinnarizine, and halofantrine). Data listed in Supplemental material 3 shows that mixed micelles composed of mono-, di, and triglycerides, which form in situ, when the triglycerides are hydrolyzed, have a higher solubilization capacity compared to pure micelles or buffer only. The increases reported are ten times higher for griseofulvin, 17 for diazepam, 178 for danazol, 1600 for cinnarizine, and a staggering 10,720 for halofantrine.

This kind of digestion buffer system can be used to simulate lipid interactions with the intestinal environment on the solubility of a drug. However, such systems still do not give a complete picture of the factors impacting solubilization in the intestine.

\section{BIORELEVANT MEDIA}

In the last decade, biorelevant media have been extensively used to determine drug solubility and as dissolution media, especially for BCS class II compounds (14 studies or $25.0 \%)(8,9,13,22,27,33,35,42,44,45,47,51,54,55)$ as well as for BCS class I (4 studies or $7.1 \%)(33,34,49,51)$, class III (2 or $3.6 \%)(33,51)$, and class IV $(2$ or $3.6 \%)(33,51)$. As mentioned, biorelevant media contain generally components which are likely present in the human GI tract such as bile salts and lecithin aiming to mimic the physiological conditions in specific segments of the GI tract; thus, in these media, $\mathrm{pH}$, osmolality, and surface tension are adapted to physiological values (75).

A precursor of biorelevant media was investigated by Macheras, Koupparis, and Tsaprounis in 1986 (82); Macheras, Koupparis, and Antimisiaris in 1988 (83); Macheras, Koupparis, and Antimisiaris in 1989 (84); Macheras, Koupparis, and Apostolelli in 1987 (85); and Macheras, Koupparis, and Antimisiaris in 1990 (86). They evaluated the dissolution profiles of drug products using milk. Macheras, Koupparis, and Tsaprounis in 1986 investigated drugs were nitrofurantoin, piroxicam, indomethacin, prednisolone, diazepam, dicumarol, and griseofulvin. The use of this medium aimed to simulate the conditions of the fed state. The first generation of biorelevant media FaSSIF and FeSSIF (fed state simulated intestinal) was published by Galia et al. (87). These authors, similarly to Macheras, Koupparis, and Tsaprounis, evaluated the dissolution profiles of acetaminophen in milk corroborating the findings previously published. The biorevelant media FaSSIF and FeSSIF were updated later on and are now known as FaSSIF-V2 and FeSSIF-V2. The main difference between FaSSIF and FaSSIF-V2 is the reduced amount of lecithin in FaSSIF-V2 as compared with FaSSIF (88). The difference between FeSSIF and FeSSIF-V2 is that the second-generation medium includes two digestion components: glyceryl monooleate and sodium oleate. Both are known to enhance the solubility and dissolution of poorly water-soluble drugs. Table II shows the composition of the different versions of FaSSIF and FeSSIF (87).

Ionization and lipophilicity play an important role in solubilization of drugs in FaSSIF-V2, compared to aqueous buffer solutions. The solubility of the strong basic drug substances showed an enhanced solubility in FaSSIF-V2 probably due to favorable electrostatic interactions with the negatively charged media. For the ionized acid drug substances, the solubility was not improved using FaSSIF-V2 compared to aqueous buffer solutions (32).

The solubility of representative acid and basic and neutral compounds, respectively mefenamic acid, ketoconazole and paracetamol, and metoprolol and danazol, was measured using FaSSIF or FaSSIF-V2. FaSSIF-V2 provided lower drug solubility values than FaSSIF for basic and neutral drugs. For acid drugs, which are ionized in the intestine, $\mathrm{pH}$ plays a more important role. The use of both fasted state media, FaSSIF and FaSSIF-V2, provides a wider range to test a drug's solubility. The results of a commercially available FaSSIF-V2 were equivalent to those for FaSSIF-V2 prepared using methylene chloride as described in the literature (88). 
Several studies have shown that drug solubility in these biorelevant media is increased compared to the solubility determined in aqueous buffer solutions (Table III), as a result of enhanced wetting and/or micellar solubilization of poorly soluble drug substances (26,32,55,89-91). Yazdanian and collaborators (2004) investigated NSAID (non-steroidal anti-inflammatory drug) in a study and showed an increased drug solubility when FeSSIF and FaSSIF instead of buffers $0.1 \mathrm{~N} \mathrm{HCl}(\mathrm{pH} 1.2), 0.02 \mathrm{M}$ citric acid $(\mathrm{pH} 5.0)$ and $0.02 \mathrm{M}$ $\mathrm{Na}_{2} \mathrm{HPO}_{4}$, and $0.02 \mathrm{M} \mathrm{NaH}_{2} \mathrm{PO} 4$ ( $\mathrm{pH} 7.4$ ) were used (90). Rinaki et al. developed a dynamic GI absorption model and showed that such solubility data generated in biorelevant media can be used as guidance for the formulation scientist in the development phase (92).

Studies from Wei and Löbenberg (55) and Okumu et al. (89) showed that the purity of the used lecithin and bile salts impact the solubility of drugs like glyburide (Supplemental material 4) and montelukast sodium (Supplemental material 5) $(55,89)$. Glyburide has a higher solubility when the purity of the lecithin and bile salts is low while montelukast sodium has a higher solubility when more than $95 \%$ pure lecithin and sodium taurocholate was used.

Recently, the composition and physicochemical properties of biorelevant media and human intestinal fluids (HIF) were reviewed by Fuchs and Dressman (2014) (93). The report indicated that the type of phospholipids and bile salts used to compose a biorelevant medium must be considered. The authors proposed that a free fatty acid as a lipolysis product of lecithin should be added. The addition of low concentrations of cholesterol would also be appropriate.

An example of such media was published by Khoshakhlagh et al. (94). They conclude that the addition of cholesterol to FaSSIF results in a physiologically adapted model fluid FaSSIF-C, which increases the solubility of poorly soluble drugs. The composition of FaSSIF-C can further be adapted and differentiated to gender-specific compositions.
Today, there are a number of different biorelevant media available representing different segments of the GI tract. They range from the stomach to the colon.

Fasted and fed state simulated gastric fluids were introduced as biorelevant media to simulate the dissolution behavior of drugs, which should be taken with or without food and dissolve in the stomach. The composition of these media is presented in Table IV (95).

Fotaki et al. (96) and Chen et al. (97) published studies using simulated colonic fluid (SCoF) (Table V). The difference is the buffer system. SCoF1 has a phosphate buffer while SCoF2 has an acetic acid buffer.

In a recent study, the solubility of 17 model drugs (Supplemental material 6) was compared between simulated biorelevant media and real human intestinal fluids. The study compared fasted HIF, fed human intestinal fluid (HIF fed) with blank FaSSIF and FeSSIF, and FaSSIF and FeSSIF, respectively (33). FaSSIF and FeSSIF were prepared with crude (low-quality) taurocholate. The comparison shows that the simulated media can be considered biorelevant for intestinal solubility estimation and gives a better estimate compared to the simple buffers when poorly soluble drugs are evaluated. They also tested different concentrations of d- $\alpha$-tocopheryl polyethylene glycol 1000 succinate (TPGS) in phosphate buffer. The correlation was not as good as for FaSSIF and FeSSIF (33).

In the present literature review, biorelevant media were used in 12 studies of $56(21.4 \%)$. The biorelevant media selected were as follows: FaSSIF (21,29,30,33,36,40,44,48,54,57); FeSSIF (21,29,33,40,48,54); fasted HIF and fed HIF (33); LQ-FaSSIF (55); and FaSSIF-V2 (32).

Other studies used media containing milk with different fat contents, protein, carbohydrates, and amino acids to mimic a digested meal and added bile components to enhance the solubility of itraconazole compared to simulated gastric fluid (26).

Table IV. Simulated Gastric Fluids in Fasted and Fed State

\begin{tabular}{|c|c|c|c|c|c|}
\hline \multirow[t]{2}{*}{ Composition } & \multirow[t]{2}{*}{ FaSSGF } & \multicolumn{3}{|c|}{ FeSSGF } & \multirow[t]{2}{*}{ SGF } \\
\hline & & Early & Middle & Late & \\
\hline Lecithin $(\mu \mathrm{M})$ & 20 & & & & \\
\hline Sodium taurocholate $(\mu \mathrm{M})$ & 80 & & & & \\
\hline Pepsin $(\mathrm{mg} / \mathrm{mL})$ & 0.1 & & & & \\
\hline Sodium chloride (mM) & 34.2 & 148 & 237.02 & 122.6 & 3.2 \\
\hline Acetic acid $(\mathrm{mM})$ & & & 17.12 & & 50 \\
\hline Sodium acetate $(\mathrm{mM})$ & & & 29.75 & & \\
\hline Orthophosphoric acid (mM) & & & & 5.5 & \\
\hline Sodium dihydrogen phosphate $(\mathrm{mM})$ & & & & 32 & \\
\hline Milk/buffer & & $1: 0$ & $1: 1$ & $1: 3$ & \\
\hline Hydrochloric acid (mL) & & & & & 7 \\
\hline $\begin{array}{l}\text { Hydrochloric acid/sodium hydroxide q.s. } \\
\text { Properties }\end{array}$ & pH 1.6 & $\mathrm{pH} 6.4$ & pH 5.0 & $\mathrm{pH} 3.0$ & \\
\hline Buffer capacity $(\mathrm{mmol} / \mathrm{L} / \Delta \mathrm{pH})$ & & 21.33 & 25 & 25 & \\
\hline $\mathrm{pH}$ & 1.6 & 6.4 & 5 & 3 & 1.2 \\
\hline Surface tension $(\mathrm{mN} / \mathrm{m})$ & 42.6 & & & & 33.7 \\
\hline Osmolality (mOsm/kg) & 120.7 & 559 & 400 & 300 & 180 \\
\hline
\end{tabular}

FaSSGF fasted state simulated gastric fluid, FeSSGF fed state simulated gastric fluid, $S G F$ simulated gastric fluid 
Table V. Composition of Simulated Colonic Fluid 1 (SCoF1) and Simulated Colonic Fluid 2 (SCoF2)

\begin{tabular}{lll}
\hline Composition & SCoF1 & SCoF2 \\
\hline Potassium chloride $(\mathrm{g})$ & 0.20 & - \\
Sodium chloride $(\mathrm{g})$ & 8.00 & - \\
Potassium phosphate monobasic $(\mathrm{g})$ & 0.24 & - \\
Sodium phosphate dibasic $(\mathrm{g})$ & 1.44 & - \\
Acetic acid $(\mathrm{g})$ & - & 10.20 \\
Sodium hydroxide $(\mathrm{g})$ & - & 6.20 \\
Deionized water to $(\mathrm{L})$ & 1.00 & 1.00 \\
Properties & & \\
pH & 7 & 5.8 \\
Osmolality (mOsmol/kg) & - & 295 \\
Buffer capacity (mEq/L/pH) & - & 29.1 \\
Ionic strength & - & 0.16 \\
\hline
\end{tabular}

SCoF1 simulated colonic fluid 1, SCoF2 simulated colonic fluid 2

As seen, different biorelevant media are available to assess drug solubility in different segments of the GI tract. However, they are still variable in their purity and batch-tobatch consistency. High-purity grades of bile salts are expensive. Additionally, they pose an analytical challenge due to their complex composition and require timeconsuming and complicated procedures (98). However, at this time point, biorelevant media as described above seem to be the best starting point to estimate in vivo solubility and estimate in vivo dissolution behavior of poorly soluble drugs.

\section{DRUG DISSOLUTION}

In 1897, Noyes and Whitney found that "the rate at which a solid substance dissolves in its own solution is proportional to the difference between the concentration of that solution and the concentration of the saturated solution" (99). Today, dissolution testing is used in pharmaceutical performance testing to determine the rate and extent of drug release from a dosage from, e.g., a tablet. Therefore, the choice of the experimental medium composition has to be based on scientific knowledge and experience (100). In this review, we focus on media evolution in dissolution testing.

\section{WATER}

When purified water is selected as a dissolution medium and not used as a solvent to determine a drug's solubility, it might have to be treated to reduce the dissolved air by suitable means, according to the USP Chapter 711 (101). Deaerated water is mentioned in USP chapter 1092 (102); the suggested methods for deaerating include warming the dissolution media to $41{ }^{\circ} \mathrm{C}$, followed by vacuum filtration through a $0.45-\mu \mathrm{m}$ pore-size-rated membrane, and vigorously stirring the filtrate while maintaining vacuum. This review showed that 6 of 20 studies $(9,14,16,22,23,34)$ used water as dissolution medium. Only one study mentioned the degassing procedure (14).

Pure water as dissolution medium has some drawbacks. For example, its characteristics can change during the test due to the influence of the active ingredients or excipients. In addition, water might not provide sink conditions for poorly soluble drugs. Sink conditions are defined as at least three times the volume necessary to obtain a saturated solution of the tested drug dose (103). In the pharmaceutical industry, dissolution testing was historically used as a quality control method for batch release and as a development tool to assess different formulations (104).

\section{BICARBONATE BUFFER}

Lately, the use of bicarbonate buffer gained interest due to their similarity with the physiological buffer systems. The use of $\mathrm{pH} 6.8$ physiological bicarbonate buffer, derived and modified from Hank's balanced salt solution, allowed the differentiation between enteric coatings of tablets. Compared to the in vitro release in compendia phosphate buffers, which was rapid, the carbonate buffers differentiated significant differences in drug release between different coating materials, which correlated with disintegration results (105).

Varum et al. (106) introduced a bicarbonate buffer, which is based on Hanks' balanced salt solution. The $\mathrm{pH} 5.6$ buffer was highly unstable and had to be maintained by an Auto $\mathrm{pH}^{\mathrm{TM}}$ System. The purpose of this buffer was to mimic the conditions of the proximal small intestine. The study showed that dissolution behavior of different coated formulations could be predicated in vitro using this buffer but not when phosphate buffer was used (Supplemental material 7).

Similarly, the dissolution behavior of mesalazine entericcoated tablet has shown that the use of bicarbonate buffer provides improved predictive power compared to compendial phosphate buffers (107). However, Boni et al. (108) emphasized that the bicarbonate buffer has to be freshly prepared to produce reproducible dissolution profiles. The improved in vivo relationship of bicarbonate buffers seems to be due to a complex and dynamic interplay between the concentration of hydrogen carbonate, carbonic acid, and the amount of dissolved and solvated carbon dioxide, as well as the ambient partial pressure of carbon dioxide. These features allow simulating dynamic intraluminal $\mathrm{pH}$ changes in the physiological range. This can be achieved in a single experiment without the need to alter the ionic strength of the solution by using an automated system (109).

As mentioned before, Krieg et al. (77) compared carbonate and phosphate buffers and its correlation of in vitro dissolution of weak acids and bases. The study concluded: "It appears that low phosphate buffer concentrations (1-25 mM) are often more physiologically relevant and may better simulate the impact of bicarbonate buffer on the dissolution of weak acid drugs. For weak base drugs, extremely low phosphate buffer concentrations $(<2 \mathrm{mM})$ would be needed to match physiologically relevant bicarbonate buffer." They point out that the currently used phosphate buffers have too high salt concentrations and do not correlate to the in vivo present carbonate buffer strengths. The authors recommend following the low buffer concentrations to gain better understanding of the impact of phosphate buffer strength on dissolution.

\section{BIORELEVANT MEDIA}

Biorelevant media are not only used to determine the solubility of a drug but are also used to perform dissolution tests. However, their analytical properties, price, and 
variability in composition exclude them from being used as routine quality control media. Several studies have shown that a dissolution test using biorelevant media for poorly soluble drugs seems to be able to mimic the in vivo dissolution better compared to other media $(55,85,110-112)$. If the in vitro dissolution matches the in vivo dissolution then computer simulations might use the dissolution profiles as input function into pharmacokinetic models. This allows establishing in vitro/in vivo correlations (IVIVC). Examples for IVIVCs using dynamic dissolution conditions and biorelevant media combined with software applications were published by Jantratid et al. (110). They identified a food effect for diclofenac sodium MR pellets using FaSSIF and FeSSIF. In addition, the correlation between fraction dose absorbed $v s$. fraction dose dissolved was superior if a dynamic dissolution flow-through model was used.

Wei and Löbenberg (55) showed that dynamic $\mathrm{pH}$ changes in biorelevant dissolution media impact the dissolution behavior of glyburide tablets and reported similar results when dissolution data were used as input function into simulation software. The dissolution data could predict in vivo observed clinical data using GastroPlus ${ }^{\mathrm{TM}}$, a software which uses the Advanced Compartmental Absorption and Transit model. Sunesen et al. (111) investigated the behavior of danazol under fasted and fed conditions, using biorelevant media. The authors found that by using a flow-through dissolution method, it was possible to achieve an IVIVC under these conditions. Okumo et al. (89) showed that a dynamic $\mathrm{pH}$ change of the dissolution media generated a release profile for montelukast sodium tablets which was able to predict the observed pharmacokinetics when used as input function into GastroPlus software. Fang et al. (113) fine-tuned the dynamic dissolution protocol and applied it to food effect studies and as a screening tool in early drug development.

However, FaSSIF and FeSSIF are not always predictive. For example, the absorption and in vivo behavior of griseofulvin were not revealed by these media (54). In this case, MREVID 2 (medium reflecting in vivo dissolution) was proposed as a new in vitro dissolution medium to mimic the in vivo dissolution behavior of poorly water-soluble drugs better. The proposed media contains 7.5 times more sodium taurocholate and phosphatidylcholine compared to FaSSIF. The maximum drug concentration of griseofulvin was $9.15 \mu \mathrm{g} /$ $\mathrm{mL}$ in FaSSIF and 3.8 times higher using MREVID 2 (35.42 $\mu \mathrm{g} / \mathrm{mL})(54)$.

\section{SURFACTANTS}

Today, regulatory agencies like the FDA 2015 (114) request that product specifications focus on clinical relevance and this might include dissolution specifications. However, biorelevant media are not practical in routine quality control due to their properties and therefore other surfactants have to be considered instead. The choice and type of surfactant are in most cases based solely on the fact that they will facilitate drug dissolution and might increases in vivo predictability.

The physicochemical characteristics of a surfactant, ionic strength of the medium, and nature of the buffer system depend on the type of drug under investigation such as in the case of mefenamic acid. The solubility of this drug is affected by a change in ionic strength when sodium lauryl sulfate (SLS) is used. Differently, cetyltrimethylammonium bromide (CTAB) did not show the same effect. In general, CTAB, SLS, and polysorbate 80 are common choices for cationic, anionic, and non-ionic surfactants (Table VI) (115).

Crison et al. (116) described an experiment where dissolution rate and solubility of piroxicam (PX) were estimated by a simple additive model for the effect of $\mathrm{pH}$ and surfactant SLS 0.5, 1.0, and $2.0(w / v \%)$. The dissolution rate was directly proportional to the diffusivity of the drugloaded micelle, and any change in the formation of the micelle impacted the dissolution process. The total drug solubility was determined by a sum of the values for the individual species, which were $\mathrm{PX}, \mathrm{PX}-$, and $[\mathrm{PX}]$ micelle. The proposed model was able to predict the dissolution and the solubility of ionizable water-insoluble drug as functions of $\mathrm{pH}$ and surfactant concentration (5). Moreover, the purity of the surfactant also must be investigated due to its significant influence in the size and loading capacity of micelles, which results in changes in solubility and dissolution rate (117).

As seen, the purity of a surfactant is an important quality attribute to obtain reproducible results. Polysorbate 80 typically has a structure that contains approximately 20 groups of polyoxyethylene (POE) per molecule. However, its synthesis process yields not only the desired monoesters but also some by-products. The analysis of polysorbate 80 using reverse-phase-HPLC and mass spectrometry revealed a complex mixture of polymeric species containing POE groups. The surfactant contained not only polyoxyethylene sorbitan monooleate (PSM) but also a number of POE intermediates such as polyoxyethylene sorbitan (PS), polyoxyethylene sorbitan dioleates (PSD), polyxoyethylene sorbitan trioleates (PStri), and polyoxyethylene sorbitan tetraoleates (PSTetra) (118). Furthermore, the fatty acid composition is approximately $70 \%$ oleic acid with several other fatty acids, which is not always the same. Therefore, other surfactants with higher purity and better-controlled composition should be considered for dissolution testing.

Polyoxyethyleneglycol dodecyl ether, commercially known as Brij 35, was used in some studies as surfactant for dissolution testing (95). The hydrophobic segment of this surfactant is of similar size and structure as the one of polysorbate, but Brij 35 has an unbranched hydrophilic PEO chain and has a single long-chain fatty acid. By choosing the number of (OE) group vs. the length of the hydrocarbon

Table VI. Commonly Used Surfactants for Dissolution Testing

\begin{tabular}{llll}
\hline Surfactant type & Anionic surfactants & Neutral surfactants & Cationic surfactants \\
\hline $\begin{array}{l}\text { Commonly used } \\
\text { surfactants }\end{array}$ & $\begin{array}{c}\text { Sodium lauryl sulfate, } \\
\text { sodium deoxycholate }\end{array}$ & $\begin{array}{c}\text { Polysorbate 20, Polysorbate } \\
80, \text { X-100, Myri-52; Brij-35 }\end{array}$ & $\begin{array}{c}\text { Cetyl trimethylammonium bromide (CTAB), } \\
\text { cetylpyridinium chloride (CPC) }\end{array}$ \\
\hline
\end{tabular}


chain, the analyst can find the right property of the surfactant to be used in dissolution method development. This might overcome variability observed with polysorbate-based surfactants (119).

In predictive dissolution testing, the micelles composed of surfactant molecules mimics the bile acid aggregates in the small intestine; the surfactant facilitates the diffusion and transport of the free solute into the bulk medium. Since dissolution is a combined effect of solubility and diffusivity, the micelle size will have an effect on the dissolution rate of molecules when different surfactants are used (120).

\section{REGULATORY VIEW OF BIOPHARMACEUTICS DRUG CLASSIFICATION SYSTEM AND SOLUBILITY}

The Biopharmaceutics Drug Classification System (BCS) determines solubility of a certain drug dose within the $\mathrm{pH}$ range of the gastrointestinal tract in up to $250 \mathrm{~mL}$ medium. The $250 \mathrm{~mL}$ refer to the volume of water, which is taken with the dosage form when administered orally (121).

The BCS assumes that a drug is highly soluble if a certain dose is soluble in $250 \mathrm{~mL}$ or less in an aqueous medium within the physiological $\mathrm{pH}$ range. The drug substance will then dissolve instantly after administration $(122,123)$.

However, different FDA guidance documents use different $\mathrm{pH}$ ranges to determine the solubility of drug substances: e.g., the biowaiver guideline from 2000 determines the solubility of the highest dose strength in $250 \mathrm{~mL}$ or less of aqueous media, over the $\mathrm{pH}$ range of $1-7.5$ at $37 \pm 1^{\circ} \mathrm{C}(124)$, while the CEDER guide from 1997 uses $\mathrm{pH}$ 1.0-8.0 (69), an FDA's draft guidance from 2015 on "Dissolution Testing and Specification Criteria for Immediate-Release Solid Oral Dosage Forms Containing Biopharmaceutics Classification System Class 1 and 3 Drugs" uses pH 1 to 6.8 (113).

Other global guidance documents such as Brazilian Health Surveillance Agency (ANVISA) and Health Canada guidance use the $\mathrm{pH}$ range of $\mathrm{pH} 1.2$ to $6.8(125,126)$. This $\mathrm{pH}$ range was accepted over the years as the most appropriate $\mathrm{pH}$ range best reflecting the in vivo conditions of the gastrointestinal tract. Today's different guidance documents use the $250 \mathrm{~mL}$ medium, but unfortunately define the dose tested differently.

The 2000 FDA guidance (124) and the 2015 draft guidance (127) measure the solubility of the highest (dose) strength in $250 \mathrm{~mL}$ of aqueous medium $(67,111,119,120)$. In contrast, the EMA guidance documents (128), WHO Technical Report (2015) (129), and Health Canada (126) require determining the solubility of the highest single dose administered, which in certain cases can be two or more units in $250 \mathrm{~mL}$ (115). This shifts many drugs into the "poorly soluble" classification category.

Sediq et al. (130) evaluated the impact on the BCS classification related with dose-solubility ratio (D/S) (expressed in volume $\mathrm{mL}$ ) of 27 drugs using the new dose definition. A reclassification of some drugs, where a biowaiver monograph was published prior to 2015 by the International Pharmaceutical Federation (FIP), was necessary. The FIP compendium currently contains over 40 monographs (131). The criterion change did not alter the BCS classification, as well as the recommendation of biowaivers, for 22 drug substances. However, for drugs such as acetazolamide, metoclopramide hydrochloride, verapamil hydrochloride, prednisolone, and prednisone, the highest single doses administered were as follows: $500 \mathrm{mg}$ $(\mathrm{D} / \mathrm{S}=406 \mathrm{~mL}), 20 \mathrm{mg}(\mathrm{D} / \mathrm{S}=472 \mathrm{~mL}), 240 \mathrm{mg}$ $(\mathrm{D} / \mathrm{S}=500 \mathrm{~mL}), 100 \mathrm{mg}(\mathrm{D} / \mathrm{S}=412 \mathrm{~mL})$, and $100 \mathrm{mg}$ $(\mathrm{D} / \mathrm{S}=752 \mathrm{~mL})$, respectively. The needed volume to dissolve the dose is above $250 \mathrm{~mL}$. These results modify the biopharmaceutical classification of these drug substances and their eligibility for a biowaiver. The authors concluded that a case-by-case review is required for drug substances close to the solubility limit $(250 \mathrm{~mL})$. The use of the EMA criterion may alter the classification of a class I drug to class II and for a class III drug to class IV, rendering them ineligible for the biowaiver procedure (130). Bioequivalence studies normally do not compare the highest administered dose but the highest dose strength.

Thus, Daousani and Macheras (132) suggest the suppression of the "highest single oral dose recommended for administration" concept in the EMA's "Summary of Product Characteristics" (133). Because dissolution kinetics are dose dependent, the dissolution requirement (\% dissolved at a specified time) may differ from the dose concepts used by FDA and EMA (132). These authors consider that it is scientifically acceptable to perform the dissolution tests based on the dose used in the actual practice to guide dose selection criteria for bioequivalence studies.

The 2015 changed WHO criterion (134) considers a "highly soluble drug" when the highest single therapeutic dose as determined by the relevant regulatory authority is soluble in $250 \mathrm{~mL}$ or less of aqueous media, over the $\mathrm{pH}$ range of $1.2-6.8$, at $37 \pm 1{ }^{\circ} \mathrm{C}$. According to this new report, the drug substance accepted for a biowaiver procedure has to be evaluated using an in vivo equivalence study, at the highest marketed strength.

On the other side, Yazdanian et al. (90) argued that the solubility criteria used by FDA for weak acids are too stringent because acids do not dissolve well in the stomach but will be highly soluble in the intestine, which is the site of drug absorption. According to their study, 15 out of the 18 tested acidic NSAIDs have to be classified as class II compounds when the solubility criteria of $\mathrm{pH} 1.2$ to 7.4 are applied. However, 15 drugs could be classified as a class I drug based on the $\mathrm{pH} 7.4$ solubility alone. The authors suggest that a $\mathrm{pH}$ solubility range between 5.0-7.4 should be applied to acetic compounds, when they are classified according to the BCS (90). The rationale of this study was integrated in the 2006 WHO biowaiver guideline (129), which allowed biowaivers for weak acids. Unfortunately, this was removed in the 2015 guideline (134).

The solubility criterion is one of two parameters to classify drug substances according to the BCS. Today, amoxicillin is a BCS class I drug substance according to the WHO list of essential drugs $(135,136)$. EMA classifies it as BCS class II drug substance due to the highest dose criterion and FDA as BCS class IV drug substance due to differences in the permeability criterion.

Overall, the BCS is a scientific approach to oral bioavailability and was introduced into regulatory sciences as a scientific risk management tool to waive bioequivalence studies under certain conditions as first done by the FDA SUPAC guideline (137). It is unfortunate that since then different guidelines have introduced slightly different 
definitions. As shown for amoxicillin, this causes more confusion than certainty for globally operating companies.

As seen, there is room for harmonization between the different guidance documents to have the same BCS class assigned for a drug substance globally, since solubility does not change just because it was determined in different countries.

\section{FINAL CONSIDERATIONS}

Herein was presented the evolution of media and buffers in the determination of a drug substance's solubility and promising trends in developing predictive dissolution media. The type of surfactant used as a potential alternative to biorelevant media has to be carefully considered. At this time point, there is no universal medium available which can be used to predict every drug substance's solubility or a drug product's in vivo dissolution behavior. However, there have been many improvements and additions made to dissolution media to optimize their in vivo predictability. The right choice of a dissolution media to predict clinical relevant dosage form attributes is still done on a case-bycase basis. Also, the dissolution apparatus has a huge impact on the shape of the dissolution profiles; however, this was not part of this review. While establishing an IVIVC for every drug molecule sounded impossible some years ago, all current developments in media composition, dissolution apparatus design, and computer simulations suggest that it might be possible in the future. Examples of how such integrated software-guided approaches can look like have been published in the past $(55,85,110,138)$. However, precise mechanistic understanding of the dissolution processes in vitro and in vivo is imperative to set clinical relevant dissolution specifications and to link in vitro dissolution to clinical outcomes.

\section{ACKNOWLEDGMENTS}

The authors extend special thanks to the Product Quality Research Institute (PQRI) for their financial support of this work and declare no potential conflicts of interest.

Open Access This article is distributed under the terms of the Creative Commons Attribution 4.0 International License (http://creativecommons.org/licenses/by/4.0/), which permits unrestricted use, distribution, and reproduction in any medium, provided you give appropriate credit to the original author(s) and the source, provide a link to the Creative Commons license, and indicate if changes were made.

\section{REFERENCES}

1. Aulton M, Taylor K. Aulton's pharmaceutics: The design and manufacture of medicines. 4th ed. London: Churchill Livingstone; 2013.

2. Higuchi T, Connors K. Phase-solubility techniques. Adv Anal Chem Instrum. 1965;7:117-212.

3. Jouyban A. Handbook of solubility data for pharmaceuticals. Boca Raton: CRC Press; 2009.

4. United States Pharmacopeial Convention. USP 38-NF 33, General notices and requirements. Rockville: United States Pharmacopeial Convention; 2015.

5. Jinno J, Oh D, Crison JR, Amidon GL. Dissolution of ionizable water-insoluble drugs: the combined effect of $\mathrm{pH}$ and surfactant. J Pharm Sci. 2000;89(2):268-74.
6. Arya P, Pathak K. Assessing the viability of microsponges as gastro retentive drug delivery system of curcumin: optimization and pharmacokinetics. Int J Pharm 2014;460(1-2):1-12.

7. Mota FL, Carneiro AP, Queimada AJ, Pinho SP, Macedo EA. Temperature and solvent effects in the solubility of some pharmaceutical compounds: measurements and modeling. Eur J Pharm Sci. 2009;37(3-4):499-507.

8. Maulvi FA, Dalwadi SJ, Thakkar VT, Soni TG, Gohel MC, Gandhi TR. Improvement of dissolution rate of aceclofenac by solid dispersion technique. Powder Technol. 2011;207(1-3):4754.

9. Goud NR, Suresh K, Nangia A. Solubility and stability advantage of aceclofenac salts. Cryst Growth Des. 2013;13(4):1590-601.

10. Kommavarapu P, Maruthapillai A, Palanisamy K, Sunkara M. Preparation and characterization of rilpivirine solid dispersions with the application of enhanced solubility and dissolution rate. Beni-Suef Univ J Basic Appl Sci. 2015;4(1):71-9.

11. Persson AM, Pettersson C, Sokolowski A. Correlation of in vitro dissolution rate and apparent solubility in buffered media using a miniaturized rotating disk equipment: part II. Comparing different buffer media. Drug Discov Ther. 2009;3(3):114-22.

12. Florindo C, Araújo JMM, Alves F, Matos C, Ferraz R, Branco L, et al. Evaluation of solubility and partition properties of ampicillin-based ionic liquids. Int J Pharm. 2013; 456(2):553-9.

13. Tomaszewska I, Karki S, Shur J, Price R, Fotaki N. Pharmaceutical characterisation and evaluation of cocrystals: importance of in vitro dissolution conditions and type of coformer. Int J Pharm. 2013;453(2):380-8.

14. Grossjohann C, Eccles KS, Maguire AR, Lawrence SE, Tajber L, Corrigan OI, et al. Characterisation, solubility and intrinsic dissolution behaviour of benzamide: dibenzyl sulfoxide cocrystal. Int J Pharm. 2012;422(1-2):24-32.

15. Prabakaran D. Effect of hydrophilic polymers on the release of diltiazem hydrochloride from elementary osmotic pumps. Int J Pharm. 2003;259(1-2):173-9.

16. Sehić S, Betz G, Hadzidedić S, El-Arini SK, Leuenberger H. Investigation of intrinsic dissolution behavior of different carbamazepine samples. Int J Pharm. 2010;386(1-2):77-90.

17. Barzegar-Jalali M, Valizadeh H, Shadbad M-RS, Adibkia K, Mohammadi G, Farahani A, et al. Cogrinding as an approach to enhance dissolution rate of a poorly water-soluble drug (gliclazide). Powder Technol. 2010;197(3):150-8.

18. Srirangam R, Majumdar S. Passive asymmetric transport of hesperetin across isolated rabbit cornea. Int $\mathrm{J}$ Pharm. 2010;394(1-2):60-7.

19. Völgyi G, Baka E, Box KJ, Comer JEA, Takács-Novák K. Study of pH-dependent solubility of organic bases. Revisit of Henderson-Hasselbalch relationship. Anal Chim Acta. 2010;673(1):40-6.

20. Gao Y, Gao J, Liu Z, Kan H, Zu H, Sun W, et al. Coformer selection based on degradation pathway of drugs: a case study of adefovir dipivoxil-saccharin and adefovir dipivoxilnicotinamide cocrystals. Int J Pharm. 2012;438(1-2):327-35.

21. Takács-Novák K, Szóke V, Völgyi G, Horváth P, Ambrus R, Szabó-Révész P. Biorelevant solubility of poorly soluble drugs: rivaroxaban, furosemide, papaverine and niflumic acid. J Pharm Biomed Anal. 2013;83:279-85.

22. Agrawal S, Panchagnula R. Dissolution test as a surrogate for quality evaluation of rifampicin containing fixed dose combination formulations. Int J Pharm. 2004;287(1-2):97-112.

23. Li S, Wong S, Sethia S, Almoazen H, Joshi YM, Serajuddin ATM. Investigation of solubility and dissolution of a free base and two different salt forms as a function of $\mathrm{pH}$. Pharm Res. 2005;22(4):628-35.

24. Bartolomei M, Bertocchi P, Antoniella E, Rodomonte A. Physico-chemical characterisation and intrinsic dissolution studies of a new hydrate form of diclofenac sodium: comparison with anhydrous form. J Pharm Biomed Anal. 2006;40(5):1105-13.

25. Baka E, Comer JEA, Takács-Novák K. Study of equilibrium solubility measurement by saturation shake-flask method using 
hydrochlorothiazide as model compound. J Pharm Biomed Anal. 2008;46(2):335-41.

26. Ghazal HS, Dyas AM, Ford JL, Hutcheon GA. In vitro evaluation of the dissolution behaviour of itraconazole in biorelevant media. Int J Pharm. 2009;366(1-2):117-23.

27. Sheng JJ, Kasim NA, Chandrasekharan R, Amidon GL. Solubilization and dissolution of insoluble weak acid, ketoprofen: effects of $\mathrm{pH}$ combined with surfactant. Eur J Pharm Sci. 2006;29(3-4):306-14.

28. Loftsson T, Matth K, Másson M. The effects of organic salts on the cyclodextrin solubilization of drugs. Int $\mathrm{J}$ Pharm. 2003;262:101-7.

29. Bard B, Martel S, Carrupt P. High throughput UV method for the estimation of thermodynamic solubility and the determination of the solubility in biorelevant media. Eur J Pharm Sci. 2007;3:230-40

30. Vogt M, Kunath K, Dressman JB. Dissolution improvement of four poorly water soluble drugs by cogrinding with commonly used excipients. Eur J Pharm Biopharm. 2008;68(2):330-7.

31. Charkoftaki G, Kytariolos J, Macheras P. Novel milk-based oral formulations: proof of concept. Int J Pharm. 2010;390(2):150-9.

32. Ottaviani G, Gosling DJ, Patissier C, Rodde S, Zhou L, Faller B. What is modulating solubility in simulated intestinal fluids? Eur J Pharm Sci. 2010;41(3-4):452-7.

33. Clarysse S, Brouwers J, Tack J, Annaert P, Augustijns P. Intestinal drug solubility estimation based on simulated intestinal fluids: comparison with solubility in human intestinal fluids. Eur J Pharm Sci. 2011;43(4):260-9.

34. Kolašinac N, Kachrimanis K, Homšek I, Grujić B, Đurić Z, Ibrić S. Solubility enhancement of desloratadine by solid dispersion in poloxamers. Int J Pharm. 2012;436(1-2):161-70.

35. Guhmann M, Preis M, Gerber F, Pöllinger N, Breitkreutz J, Weitschies W. Development of oral taste masked diclofenac formulations using a taste sensing system. Int $\mathrm{J}$ Pharm. 2012;438(1-2):81-90.

36. Niederquell A, Kuentz M. Biorelevant dissolution of poorly soluble weak acids studied by UV imaging reveals ranges of fractal-like kinetics. Int J Pharm. 2014;463(1):38-49.

37. Thing M, Jensen SS, Larsen C, Østergaard J, Larsen SW. Modification of concomitant drug release from oil vehicles using drug-prodrug combinations to achieve sustained balanced analgesia after joint installation. Int $\mathrm{J}$ Pharm. 2012;439(1-2):246-53.

38. Baek J, Lim J, Kang J, Shin S, Jung S, Cho C. Enhanced transdermal drug delivery of zaltoprofen using a novel formulation. Int J Pharm. 2013;453(2):358-62.

39. Box KJ, Völgyi G, Baka E, Stuart M, Takács-Novák K, Comer JE. Equilibrium versus kinetic measurements of aqueous solubility, and the ability of compounds to supersaturate in solution - a validation study. J Pharm Sci. 2006;95:1298-307.

40. Do TT, Van Speybroeck M, Mols R, Annaert P, Martens J, Van Humbeeck $\mathrm{J}$, et al. The conflict between in vitro release studies in human biorelevant media and the in vivo exposure in rats of the lipophilic compound fenofibrate. Int J Pharm. 2011;414(1-2):118-24.

41. Dokoumetzidis A, Papadopoulou V, Valsami G, Macheras P. Development of a reaction-limited model of dissolution: application to official dissolution tests experiments. Int $\mathbf{J}$ Pharm. 2008;355:114-25.

42. Dressman JB, Nair A, Abrahamsson B, Barends DM, Groot DW, Kopp S, et al. Biowaiver monograph for immediaterelease solid oral dosage forms: acetylsalicylic acid. J Pharm Sci. 2012;101:2653-67.

43. El-Gendy AM, Adejare A. Membrane permeability related physicochemical properties of a novel gamma-secretase inhibitor. Int J Pharm. 2004;280(1-2):47-55.

44. Fischer SM, Parmentier J, Buckley ST, Reimold I, Brandl M, Fricker G. Oral bioavailability of ketoprofen in suspension and solution formulations in rats: the influence of poloxamer 188. J Pharm Pharmacol. 2012;64(11):1631-7.

45. Gao Y, Liao J, Qi X, Zhang J. Coamorphous repaglinidesaccharin with enhanced dissolution. Int J Pharm. 2013;450(12):290-5.

46. Kaur M, Kaur R, Pissurlenkar RRS, Coutinho EC, Kumar U, Prakash $\mathrm{O}$, et al. Telmisartan complex augments solubility, dissolution and drug delivery in prostate cancer cells. Carbohydr Polym. 2014;101:614-22.

47. Kumar L, Jog R, Singh S, Bansal A. Effect of counterion on the solid state photodegradation behavior of prazosin salts. AAPS PharmSciTech. 2013;14(2):757-63.

48. Levis KA, Lane ME, Corrigan OI. Effect of buffer media composition on the solubility and effective permeability coefficient of ibuprofen. Int J Pharm. 2003;253(1-2):49-59.

49. Nair A, Abrahamsson B, Barends DM, Groot DW, Kopp S, Polli $\mathrm{JE}$, et al. Biowaiver monographs for immediate release solid oral dosage forms: amodiaquine hydrochloride. 2012;101(12):4390-401.

50. Nokhodchi A, Shokri J, Dashbolaghi A, Hassan-Zadeh D, Ghafourian T, Barzegar-Jalali M. The enhancement effect of surfactants on the penetration of lorazepam through rat skin. Int J Pharm. 2003;250(2):359-69.

51. Zakeri-Milani P, Barzegar-Jalali M, Azimi M, Valizadeh H. Biopharmaceutical classification of drugs using intrinsic dissolution rate (IDR) and rat intestinal permeability. Eur J Pharm Biopharm. 2009;73(1):102-6.

52. Avdeef A, Tsinman O. Miniaturized rotating disk intrinsic dissolution rate measurement: effects of buffer capacity in comparisons to traditional wood's apparatus. Pharm Res. 2008;25(11):2613-27.

53. Berger CM, Tsinman O, Voloboy D, Lipp D, Stones S, Avdeef A. Technical note: miniaturized intrinsic of griseofulvin and carbamazepine. Dissolution Technol. 2007;(1):39-41.

54. Fujioka Y, Kadono K, Fujie Y, Metsugi Y, Ogawara K, Higaki $\mathrm{K}$, et al. Prediction of oral absorption of griseofulvin, a BCS class II drug, based on GITA model: utilization of a more suitable medium for in-vitro dissolution study. J Control Release. 2007;119(2):222-8.

55. Wei H, Löbenberg R. Biorelevant dissolution media as a predictive tool for glyburide a class II drug. Eur J Pharm Sci. 2006;29(1):45-52.

56. Yu LX, Carlin AS, Amidon GL, Hussain AS. Feasibility studies of utilizing disk intrinsic dissolution rate to classify drugs. Int J Pharm. 2004;270:221-7.

57. Fong SYK, Ibisogly A, Bauer-Brandl A. Solubility enhancement of BCS class II drug by solid phospholipid dispersions: spray drying versus freeze-drying. Int $\mathrm{J}$ Pharm. 2015;496(2):382-91.

58. Marano S, Barker SA, Raimi-Abraham BT, Missaghi S, Rajabi-Siahboomi A, Craig DQM. Development of microfibrous solid dispersions of poorly water-soluble drugs in sucrose using temperature-controlled centrifugal spinning. Eur J Pharm Biopharm. 2016;103:84-94.

59. Kambayashi A, Yasuji T, Dressman JB. Prediction of the precipitation profiles of weak base drugs in the small intestine using a simplified transfer ("dumping") model coupled with in silico modeling and simulation approach. Eur J Pharm Biopharm. 2016;103:95-103.

60. Bergström CAS, Luthman K, Artursson P. Accuracy of calculated $\mathrm{pH}$-dependent aqueous drug solubility. Eur J Pharm Sci. 2004;22(5):387-98.

61. Völgyi G, Marosi A, Takács-Novák K, Avdeef A. Salt solubility products of diprenorphine hydrochloride, codeine and lidocaine hydrochlorides and phosphates - novel method of data analysis not dependent on explicit solubility equations. ADMET DMPK. 2013;1(4):48-62.

62. Avdeef A. Anomalous solubility behavior of several acidic drugs. ADMET DMPK. 2014;2(1):33-42.

63. Fini A. Solubility and solubilization properties of non-steroidal anti-inflammatory drugs. Int J Pharm. 1995;126(1-2):95-102.

64. Higuchi T, Gupta M, Busse LW. Influence of electrolytes, $\mathrm{pH}$, and alcohol concentration on the solubilities of acidic drugs. $\mathbf{J}$ Am Pharm Assoc (Scientific ed). Wiley Subscription Services, Inc., A Wiley Company; 1953 Mar;42(3):157-61.

65. Fadda HM, Merchant HA, Arafat BT, Basit AW. Physiological bicarbonate buffers: stabilisation and use as dissolution media for modified release systems. Int J Pharm. 2009;382(1-2):5660.

66. Klein S. The use of biorelevant dissolution media to forecast the in vivo performance of a drug. AAPS J. 2010;12(3):397406. 
67. Li Z, He X. Physiologically based in vitro models to predict the oral dissolution and absorption of a solid drug delivery system. Curr Drug Metab. 2015;16(9):777-806.

68. U.S. Food and Drug Administration. Guidance for Industry: Dissolution testing of immediate release solid oral dosage forms. U.S. Department of Health and Human Services Food and Drug Administration Center for Drug Evaluation and Research (CDER),1997. http://www.fda.gov/downloads/drugs/ guidancecomplianceregulatoryinformation/guidances/ ucm070237.pdf. Accessed 11 Nov 2016.

69. Dressman JB, Vertzoni M, Goumas K, Reppas C. Estimating drug solubility in the gastrointestinal tract. Adv Drug Deliv Rev. 2007;59(7):591-602.

70. United States Pharmacopeial Convention. USP 38-NF 33, drug release $<724>$. Rockville: United States Pharmacopeial Convention; 2015

71. United States Pharmacopeial Convention. USP 40-NF 35, Update: Dissolution methods database. Rockville: United States Pharmacopeial Convention; 2017. http://www.usp.org/ sites/default/files/usp_pdf/EN/USPNF/compendialTools/ dissolution_methods_database.xlsx. Accessed 20 Nov 2016.

72. Stippler E, Kopp S, Dressman JB. Comparison of US Pharmacopeia simulated intestinal fluid TS (without pancreatin) and phosphate standard buffer $\mathrm{pH} 6.8$, TS of the International Pharmacopoeia with respect to their use in in vitro dissolution testing. Dissolution Technol. 2004;11(2):610 .

73. Almukainzi M, Salehi M, Bou-Chacra N, Löbenberg R. Investigation of the performance of the disintegration test for dietary supplements. AAPS J. 2010;12(4):602-7.

74. Ropers MH, Czichocki G, Brezesinski G. Counterion effect on the thermodynamics of micellization of alkyl sulfates. J Phys Chem B Am Chem Soc. 2003;107(22):5281-8

75. Khan MZI, Rausl D, Radosević S, Filić D, Danilovski A, Dumić $\mathrm{M}$, et al. Classification of torasemide based on the Biopharmaceutics Classification System and evaluation of the FDA biowaiver provision for generic products of class I drugs. J Pharm Pharmacol. 2006;58(11):1475-82.

76. Jantratid E, Janssen N, Reppas C, Dressman JB. Dissolution media simulating conditions in the proximal human gastrointestinal tract: an update. Pharm Res. 2008;25(7):1663-76.

77. Krieg BJ, Taghavi SM, Amidon GL, Amidon GE. In vivo predictive dissolution: comparing the effect of bicarbonate and phosphate buffer on the dissolution of weak acids and weak bases. J Pharm Sci. 2015;104(9):2894-904.

78. Rangel-Yagui CO, Pessoa A, Tavares LC. Micellar solubilization of drugs. J Pharm Pharm Sci. 2005;8(2):147-63.

79. Zangenberg NH, Müllertz A, Gjelstrup Kristensen H, Hovgaard L. A dynamic in vitro lipolysis model. Eur J Pharm Sci. 2001;14(3):237-44.

80. Ottaviani G, Wendelspiess S, Alvarez-Sánchez R. Importance of critical micellar concentration for the prediction of solubility enhancement in biorelevant media. Mol Pharm. 2015;12(4):1171-9.

81. Kaukonen AM, Boyd BJ, Porter CJH, Charman WN. Drug solubilization behavior during in vitro digestion of simple triglyceride lipid solution formulations. Pharm Res. 2004;21(2):245-53.

82. Macheras P, Koupparis M, Tsaprounis C. Drug dissolution studies in milk using the automated flow injection serial dynamic dialysis technique. Int J Pharm. 1986;33(1-3):125-36.

83. Macheras PE, Koupparis MA, Antimisiaris SG. Effect of temperature and fat content on the binding of hydrochlorothiazide and chlorothiazide to milk. J Pharm Sci. 1988;77(4):334-6.

84. Macheras P, Koupparis M, Antimisiaris S. An in vitro model for exploring $\mathrm{CR}$ theophylline-milk fat interactions. Int $\mathrm{J}$ Pharm. 1989;54(2):123-30.

85. Macheras P, Koupparis M, Apostolelli E. Dissolution of 4 controlled-release theophylline formulations in milk. Int $\mathrm{J}$ Pharm. 1987;36(1):73-9.

86. Macheras PE, Koupparis MA, Antimisiaris SG. Drug binding and solubility in milk. Pharm Res. 1990;7(5):537-41.

87. Galia E, Nicolaides E, Hörter D, Löbenberg R, Reppas C, Dressman JB. Evaluation of various dissolution media for predicting in vivo performance of class I and II drugs. Pharm Res. 15(5):698-705.

88. Leigh M, Kloefer B, Schaich M. Comparison of the solubility and dissolution of drugs in fasted-state biorelevant media
(FaSSIF and FaSSIF-V2). Dissolution Technol. 2013;44-50. doi:10.14227/DT200313P44.

89. Okumu A, DiMaso M, Löbenberg R. Dynamic dissolution testing to establish in vitro/in vivo correlations for montelukast sodium, a poorly soluble drug. Pharm Res. 2008;25(12):2778-85.

90. Yazdanian M, Briggs K, Jankovsky C, Hawi A. The "high solubility" definition of the current FDA Guidance on Biopharmaceutical Classification System may be too strict for acidic drugs. Pharm Res. 2004;21:293-9.

91. Chen J, Mosquera-Giraldo LI, Ormes JD, Higgins JD, Taylor LS. Bile salts as crystallization inhibitors of supersaturated solutions of poorly water-soluble compounds. Cryst Growth Des. 2015;15(6):593-7.

92. Rinaki E, Dokoumetzidis A, Valsami G, Macheras P. Identification of biowaivers among class II drugs: theoretical justification and practical examples. Pharm Res. 2004;21(9):1567-72.

93. Fuchs A, Dressman JB. Composition and physicochemical properties of fasted-state human duodenal and jejunal fluid: a critical evaluation of the available data. J Pharm Sci. 2014;103(11):3398-411.

94. Khoshakhlagh $\mathrm{P}$, Johnson $\mathrm{R}$, Langguth $\mathrm{P}$, Nawroth $\mathrm{T}$, Schmueser L, Hellmann N, et al. Fasted-state simulated intestinal fluid "FaSSIF-C", a cholesterol containing intestinal model medium for in vitro drug delivery development. J Pharm Sci. 2015;104(7):2213-24.

95. Vertzoni M, Dressman J, Butler J, Hempenstall J, Reppas C. Simulation of fasting gastric conditions and its importance for the in vivo dissolution of lipophilic compounds. Eur J Pharm Biopharm. 2005;60(3):413-7.

96. Fotaki N, Symillides M, Reppas C. In vitro versus canine data for predicting input profiles of isosorbide-5-monohydrate from oral extended release products on a confidence interval basis. Eur J Pharm Sci. 2005;24(1):115-22.

97. Chen L, Li X, Pang Y, Li L, Zhang X, Yu L. Resistant starch as a carrier for oral colon-targeting drug matrix system. J Mater Sci Mater Med. 2007;18(11):2199-203.

98. Baxevanis F, Kuiper J, Fotaki N. Fed-state gastric media and drug analysis techniques: current status and points to consider. Eur J Pharm Biopharm. 2016;107:234-48.

99. Noyes AA, Whitney WR. The rate of solution of solid substances in their own solutions. J Am Chem Soc. 1897;19(12):930-4.

100. Azarmi S, Roa W, Löbenberg R. Current perspectives in dissolution testing of conventional and novel dosage forms. Int J Pharm. 2007;328(1):12-21.

101. United States Pharmacopeial Convention. USP 38-NF 33, dissolution $<711>$. Rockville: United States Pharmacopeial Convention; 2015.

102. United States Pharmacopeial Convention. USP 38-NF 33, the dissolution procedure <1092>. Rockville: United States Pharmacopeial Convention; 2015.

103. Brown W, Marques M. Question and answer section, Dissolution Technologies. 2003. http://www.dissolutiontech.com/ DTresour/0203art/DTFeb03_Q_A.pdf. Accessed 15 Nov 2016.

104. Dokoumetzidis A, Macheras P. A century of dissolution research: from Noyes and Whitney to the biopharmaceutics classification system. Int J Pharm. 2006;321(1-2):1-11.

105. Liu F, Merchant HA, Kulkarni RP, Alkademi M, Basit AW. Evolution of a physiological pH 6.8 bicarbonate buffer system: application to the dissolution testing of enteric coated products. Eur J Pharm Biopharm. 2011;78(1):151-7.

106. Varum FJO, Merchant HA, Goyanes A, Assi P, Zboranová V, Basit AW. Accelerating the dissolution of enteric coatings in the upper small intestine: evolution of a novel $\mathrm{pH} 5.6$ bicarbonate buffer system to assess drug release. Int J Pharm. 2014;468(1-2):172-7.

107. McConnell EL, Fadda HM, Basit AW. Gut instincts: explorations in intestinal physiology and drug delivery. Int J Pharm. 2008;364(2):213-26.

108. Boni JE, Brickl RS, Dressman J. Is bicarbonate buffer suitable as a dissolution medium? J Pharm Pharmacol. 2007;59(10):1375-82.

109. Garbacz G, Kołodziej B, Koziolek M, Weitschies W, Klein S. A dynamic system for the simulation of fasting luminal $\mathrm{pH}$-gradients using hydrogen carbonate buffers for dissolution testing of ionisable compounds. Eur J Pharm Sci. 2014;51:224-31. 
110. Jantratid E, De Maio V, Ronda E, Mattavelli V, Vertzoni M, Dressman JB. Application of biorelevant dissolution tests to the prediction of in vivo performance of diclofenac sodium from an oral modified-release pellet dosage form. Eur J Pharm Sci. 2009;37(3-4):434-41.

111. Sunesen VH, Pedersen BL, Kristensen HG, Müllertz A. In vivo in vitro correlations for a poorly soluble drug, danazol, using the flow-through dissolution method with biorelevant dissolution media. Eur J Pharm Sci. 2005;24(4):305-13.

112. Alsenz J, Haenel E, Anedda A, Du Castel P, Cirelli G. Miniaturized intrinsic dissolution screening (MINDISS) assay for preformulation. Eur J Pharm Sci. 2016;87:3-13.

113. Fang JB, Robertson VK, Rawat A, Flick T, Tang ZJ, Cauchon NS, et al. Development and application of a biorelevant dissolution method using USP apparatus 4 in early phase formulation development. Mol Pharm. 2010;7(5):1466-77.

114. U.S. Food and Drug Administration. Draft Guidance for Industry: Dissolution testing and specification criteria for immediate release solid oral dosage forms containing Biopharmaceutics Classification System class 1 and class 3 drugs. U.S. Department of Health and Human Services Food and Drug Administration Center for Drug Evaluation and Research (CDER), 2015. https://www.fda.gov/downloads/ Drugs/Guidances/UCM456594.pdf. Accessed 15 Jan 2017.

115. Park S-H, Choi H-K. The effects of surfactants on the dissolution profiles of poorly water-soluble acidic drugs. Int $\mathrm{J}$ Pharm. 2006;321(1-2):35-41.

116. Crison JR, Weiner ND, Amidon GL. Dissolution media for in vitro testing of water-insoluble drugs: effect of surfactant purity and electrolyte on in vitro dissolution of carbamazepine in aqueous solutions of sodium lauryl sulfate. J Pharm Sci. 1997;86(3):384-8.

117. Qiang D, Gunn JA, Schultz L, Li ZJ. Evaluation of the impact of sodium lauryl sulfate source variability on solid oral dosage form development. Drug Dev Ind Pharm. 2010;36(12):1486-96.

118. Zhang R, Wang Y, Tan L, Zhang HY, Yang M. Analysis of polysorbate 80 and its related compounds by RP-HPLC with ELSD and MS detection. J Chromatogr Sci. 2012;50(7):598-607.

119. Christiansen A, Backensfeld T, Kühn S, Weitschies W. Stability of the non-ionic surfactant polysorbate 80 investigated by HPLC-MS and charged aerosol detector. Pharmazie. 2011;66(9):666-71.

120. Fotaki N, Brown W, Kochling J, Chokshi H, Miao H, Tang K, et al. Rationale for selection of dissolution media: three case studies. Dissolution Technol. 2013;20(3):6-13.

121. Löbenberg R, Amidon GL. Modern bioavailability, bioequivalence and biopharmaceutics classification system. New scientific approaches to international regulatory standards. Eur J Pharm Biopharm. 2000;50(1):3-12.

122. Amidon GL, Lennernäs H, Shah VP, Crison JR. A theoretical basis for a biopharmaceutic drug classification: the correlation of in vitro drug product dissolution and in vivo bioavailability. Pharm Res. 1995;12(3):413-20.

123. Shah VP, Amidon GL. G.L. Amidon, H. Lennernas, V.P. Shah, and J.R. Crison. A theoretical basis for a biopharmaceutic drug classification: the correlation of in vitro drug product dissolution and in vivo bioavailability, Pharm Res 12, 413-420, 1995-backstory of BCS. AAPS J. 2014 Sep ;16(5):894-8.

124. U.S. Food and Drug Administration. Guidance for Industry: waiver of in vivo bioavailability and bioequivalence studies for immediate-release solid oral dosage forms based on a Biopharmaceutics Classification System. U.S. Department of Health and Human Services Food and Drug Administration Center for Drug Evaluation and Research (CDER), 2000. https://www.fda.gov/OHRMS/DOCKETS/98fr/3657gd3.pdf. Accessed 15 Jan 2017

125. Brazilian Health Surveillance Agency. Nota Técnica n. 003/ 2013/CEFAR/GTFAR/CGMED/ANVISA. 2013. http:// portal.anvisa.gov.br/documents/33836/349757/Nota + t\%
C3\% A9cnica+n \% C2\%BA+03+de+2013+-+CEFAR-GTFARGGMED-Anvisa/2c769030-a303-4c8f-adc8-5fd781695725. Accessed 14 Nov 2016.

126. Health Canada. Guidance document: Biopharmaceutics Classification System based biowaiver. 2014. http://www.hc-sc.gc.ca/ dhp-mps/alt_formats/pdf/prodpharma/applic-demande/guideld/bcs_guide_ld_scb-eng.pdf. Accessed 15 Nov 2016.

127. U.S. Food and Drug Administration. Draft Guidance for Industry: waiver of in vivo bioavailability and bioequivalence studies for immediate-release solid oral dosage forms based on a Biopharmaceutics Classification System. U.S. Department of Health and Human Services Food and Drug Administration Center for Drug Evaluation and Research (CDER), 2015. https://www.fda.gov/downloads/Drugs/Guidances/ ucm070246.pdf. Accessed 15 Jan 2017.

128. European Medicines Agency. Committee for Medicinal Products for Human Use (CHMP). 2008. Draft Guideline on the investigation of bioequivalence. http://www.ema.europa.eu/ docs/en_GB/document_library/Scientific_guideline/2009/09/ WC500003011.pdf. Accessed 14 Nov 2016.

129. World Health Organization. Annex 8 Proposal to waive in vivo bioequivalence requirements for WHO Model List of Essential Medicines immediate-release, solid oral dosage forms. Technical Report Series, No. 937, 2006. http://www.who.int/medicines/ areas/quality_safety/quality_assurance/ProposalWaiveVivo BioequivalenceRequirementsModelListEssentialMedicinesImmediateReleaseSolidOralDosageFormsTRS937Annex8.pdf. Accessed 15 Nov 2016.

130. Sediq A, Kubbinga M, Langguth P, Dressman J. The impact of the EMA change in definition of "dose" on the BCS dosesolubility ratio: a review of the biowaiver monographs. J Pharm Sci. 2014;103(1):65-70.

131. International Pharmaceutical Federation. The Netherlands. Special interest group on Biopharmaceutics Classification System (BCS) and biowaiver. http://www.fip.org/bcs. Accessed 15 Feb 2017.

132. Daousani C, Macheras P. Scientific considerations concerning the EMA change in the definition of "dose" of the BCS-based biowaiver guideline and implications for bioequivalence. Int $\mathbf{J}$ Pharm. 2015;478(2):606-9.

133. European Medicines Agency. A guideline on summary of product characteristics (SmPC). 2009. http://ec.europa.eu/ health//sites/health/files/files/eudralex/vol-2/c/ smpc_guideline_rev2_en.pdf. Accessed 14 Nov 2016.

134. World Health Organization. Multisource (generic) pharmaceutical products: guidelines on registration requirements to establish interchangeability. Technical Report Series, No. 992, Forty-ninth Report, Annex 7 of WHO Expert Committee on Specifications for Pharmaceutical Products. 2015. http:// www.who.int/medicines/areas/quality_safety/quality_assurance/ Annex7-TRS992.pdf. Accessed 15 Nov 2016.

135. Löbenberg R, Chacra NB, Stippler ES, Shah VP, DeStefano AJ, Hauck WW, et al. Toward global standards for comparator pharmaceutical products: case studies of amoxicillin, metronidazole, and zidovudine in the Americas. AAPS J. 2012;14(3):462-72.

136. World Health Organization. WHO model list of essential medicines. 2015. http://www.who.int/medicines/publications/essentialmedicines/ EML_2015_FINAL_amended_NOV2015.pdf?ua=1. Accessed 25 Nov 2016.

137. U.S. Food and Drug Administration. Guidance for Industry: Immediate release solid oral dosage forms scale-up and postapproval changes: chemistry, manufacturing, and controls, in vitro dissolution testing, and in vivo bioequivalence documentation. U.S. Department of Health and Human Services Food and Drug Administration Center for Drug Evaluation and Research (CDER), 1995. https://www.fda.gov/downloads/ drugs/guidances/ucm070636.pdf. Accessed November, 2016.

138. McAllister M. Dynamic dissolution: a step closer to predictive dissolution testing? Mol Pharm. 2010;7(5):1374-87. 